Int. J. Electrochem. Sci., 13 (2018) 5005 - 5015

\title{
Detection of Sunset Yellow by Adsorption Voltammetry at Glassy Carbon Electrode Modified with Chitosan
}

\author{
Andres Peña-Gonzalez, Olimpo García-Beltrán, Edgar Nagles* \\ Facultad de Ciencias Naturales y Matemáticas, Universidad de Ibagué, Carrera 22 Calle 67, \\ Ibagué730001, Colombia \\ *E-mail: edgar.nagles@unibague.edu.co
}

doi: $10.20964 / 2018.05 .35$

Received: 31 January 2018 / Accepted: 5 March 2018 / Published: 10 April 2018

The simple modification of the surface of a glassy carbon electrode with chitosan (CS) allowed the development of a electroanalytical method useful for the detection and quantification of sunset yellow (SY-E110) by square wave adsorption voltammetry (SWAdV). The electrode surface was characterized with electrochemical impedance spectroscopy (EIS) and cyclic voltammetry (CV). The results showed that the presence of CS on the surface of the electrode, allowed the oxidation of the SY to $1.01 \mathrm{~V}$ in a process controlled by adsorption. Under optimal conditions ( $\mathrm{pH} 2.5, \mathrm{t}_{\mathrm{ADS}} 60 \mathrm{~s}, \mathrm{E}_{\mathrm{ADS}} 0.10$ $\mathrm{V}$ ) the anodic peak current was proportional to the concentration of SY between 0.25 to $3.25 \mu \mathrm{mol} \mathrm{L} \mathrm{L}^{-1}$, with a limit of detection of $0.098 \mu \mathrm{mol} \mathrm{L}^{-1}$. The relative standard deviation (RSD) for a solution with $0.080 \mathrm{mmol} \mathrm{L}^{-1}$ of E110 was $2.5 \%$ for five different electrodes $(\mathrm{n}=5)$. The method was validated with unflavored gelatin samples spiked with known amounts of SY. The potential interferences of other synthetic dyes were studied and finally the method was tested with real samples of foods containing SY and other synthetic dyes. The results were equally acceptable compared to previous reports.

Keywords: Sunset Yellow; Adsorption voltammetry; Glassy carbon; Chitosan; modified electrodes.

\section{FULL TEXT}

(C) 2018 The Authors. Published by ESG (www.electrochemsci.org). This article is an open access article distributed under the terms and conditions of the Creative Commons Attribution license (http://creativecommons.org/licenses/by/4.0/). 